\title{
LÍMITES EN EL EJERCICIO DE LA LIBERTAD DE IMPRENTA. EL PROCESO DE LAS CORTES DE CÁDIZ CONTRA EL ROBESPIERRE ESPAÑOL
}

\author{
Jesús López de Lerma Galán \\ jllerma2002@yahoo.es
}

\begin{abstract}
Resumen: En este artículo se explican los principales problemas que los diputados de las Cortes de Cádiz encuentran en la aplicación del reglamento sobre libertad de imprenta de 1810. Los debates políticos suscitados por la publicación El Robespierre Español sirven de ejemplo para conocer las deficiencias de la naciente legislación de prensa.
\end{abstract}

Palabras claves: Cortes, periódico liberal, reglamento, libertad de prensa, ley.

Abstract: In this article are explained the principal problems that the deputies of the Spanish Parliament of Cadiz find in the application of the regulation on freedom of press of 1810. The political debates provoked by the publication The Robespierre Español use as example to know the deficiencies of the nascent legislation of press.

Keywords: Courts, liberal newspaper, regulation, press freedom, law.

\section{INTRODUCCIÓN. EL ORIGEN DE EL ROBESPIERRE ESPAÑOL}

a aprobación por las Cortes de Cádiz del primer decreto sobre libertad de imprenta en el año 1810 supuso para muchos políticos de la época una amenaza. El miedo a una prensa imparable, que influía en la sociedad y traspasaba los límites éticos, motivó la aplicación de medidas como el secuestro de ejemplares de periódicos por parte de las instituciones y autoridades. Los contenidos de ciertas publicaciones irritaban a los políticos, lo que promovió debates muy intensos en Cádiz, sobre la legitimidad de una publicación para expresar determinadas ideas y opiniones.

Uno de los procesos más interesantes que se produjo en aquel momento fue el del número 10 de la publicación el Robespierre Español, objeto de este artículo. Los debates de las Cortes de Cádiz suscitados por este caso sirven como vehículo para entender las deficiencias de la legislación de imprenta. En el desarrollo de este tema se han utilizado fuentes originales como los Diarios de Sesiones de las Cortes de Cádiz de 1811, destacando las participaciones de algunos de los principales diputados que intervinieron en los debates.

Dentro del contexto histórico hay que señalar que El Robespierre Español, amigo de las leyes o cuestiones atrevidas sobre España fue editado y redactado 
Límites en el ejercicio de la libertad de imprenta. El proceso de las cortes de Cádiz contra el Robespierre español

por el médico Pascasio Fernández Sardino, exaltado, patriota y revolucionario, y su esposa la portuguesa María del Carmen Silva (Tobajas, 1984: 162). Apareció en la Isla de León y en Cádiz en el mes de marzo de 1811 y dejó de salir en 1812. Su título muestra el tono liberal exaltado con el que se caracterizará la publicación, propio de la postura avanzada y revolucionaria de Sardino (Solís, 1971: 72 y VV. AA, 2006: 65-66). Esta publicación nació sin la menor intención de ser informativa, tan sólo fue un elemento difusor de las ideas de su autor (Gómez, 1967: 95). Surgió en pleno desarrollo de la libertad de imprenta con la intención de enfrentarse a las estructuras de poder de forma extrema, antirreligiosa y revolucionaria, una actitud que no gustó ni a los propios liberales, que veían en este periódico un tono exaltado que no respetaba los principios básicos de las Cortes.

Desde sus inicios este periódico se ve envuelto en juicios y arrestos de publicaciones, centrando muchos de los debates de las Cortes por los excesos cometidos. Los ataques que Fernández Sardino realizó contra los generales Carrafa y Urbina, pidiendo que fuesen juzgados públicamente, y el Ministro de la Guerra, motivan que el Gobierno lo mande detener y confisque sus papeles (Seoane, 1992: 48). La rendición de Badajoz a los franceses, tras un controvertido acuerdo de las autoridades, motivó el traslado de Fernández Sardino a Cádiz. Desde su primer número El Robespierre acusó a los militares por la capitulación de Badajoz, una situación controvertida, que preocupó a toda la población, y que Fernández Sardino denunció en su publicación, haciendo incluso proposiciones para ver a algún general en la horca. Nunca vio con buenos ojos la Regencia y no le gustaban las actitudes moderadas o prudentes. Las críticas contra el general Imaz, responsable militar de la plaza de Badajoz, y el general Carrafa, por su conducta en Lisboa al ser desarmadas las tropas españolas por Junot, motivaron varias denuncias contra el periódico: una firmada por el duque de Híjar y otros grandes de España residentes en Cádiz y la otra por el Teniente General Juan Carrafa. El 9 de junio de 1811 se remite a la Junta de Censura Provincial los siete primeros números del periódico, iniciándose un proceso. Finalmente la Junta de Censura de Cádiz no halló delito alguno en los cincos primeros números pero los dos siguientes fueron considerados subversivos (La Parra, 1984: 106-107).

Este periódico, se caracterizó por los ataques a la aristocracia y los elogios al pueblo, elementos que conforman muchos de sus artículos, empañados por el sentimiento y la revancha moral. Estaba mal escrito y en numerosas ocasiones recurrió al plagio. También destacó por representar la postura periodística más revolucionaria y antirreligiosa, ganándose muchos enemigos; así, en Cádiz, salieron impresos que lo criticaban como la publicación el Azote de Robespierre, que pide la muerte para Fernández Sardino (Solís, 1971: 73). Hay que señalar que, con el fin de atacar y rebatir las posiciones del Robespierre, nacen publicaciones como el Cachi-diablo, que defendía la Inquisición y del que salen dos números en julio y agosto (Solís, 1987: 337). El mero título del Robespierre y su patente exaltación era una auténtica provocación para muchos políticos y ciudadanos. Además, El Robespierre incurrió en errores y fallos que fueron utilizados por sus 
enemigos para humillarlo y hundirlo. Así, el erudito y malévolo Gallardo destacó en el Cachi-diablo que Sardino plagiaba a Saavedra Fajardo, escribiendo un artículo gracioso en el número 13 de El Redactor General donde comenta el caso, titulado "Carta del Cachi-diablo andaluz al Robespierre español" (Seoane, 1992: 72). Había diversos frentes de opinión que crearon todo un panorama de apoyos y traiciones en un escenario político donde la prensa dejaba una importante impronta. El Robespierre no fue ajeno a las críticas de otras publicaciones que, en su afán de acaparar protagonismo y ganarse el apoyo de determinadas facciones de poder, vertían insultos contra su competidor. La falta de profesionalidad de Fernández Sardino en el tratamiento de determinados asuntos, y la copia de contenidos, fue la excusa perfecta para que otras publicaciones intentaran hundirlo.

El Robespierre se prohibió al llegar al número 10. Fernández Sardino es detenido y encarcelado durante seis meses, por lo que se hace cargo de la publicación su esposa Carmen Silva que, si bien adopta un tono menos violento, no ceja en su empeño de defender a su marido calificando la detención de injusta (Seoane, 1992: 72). El número 11 salió el 27 de septiembre de 1811, y durante algún tiempo siguió publicándose, con menor éxito, que en sus inicios, y a pesar de la indignación que representaba para los antirreformistas y periódicos como El Censor General (Solís, 1971: 73). En pleno desarrollo del liberalismo y de la libertad de imprenta volvemos a encontrar las fórmulas del Antiguo Régimen y del despotismo para acabar con la prensa. Todo ello con el apoyo de las Cortes.

Los ataques contra la Regencia y las altas figuras del Gobierno, que motivan la detención de Sardino tuvieron un importante reflejo en la prensa de la época y en los sectores políticos. Los serviles atacan con ferocidad a Sardino. Los liberales, que no comparten sus ideas, defienden la libertad de prensa y que las suspensiones de los periódicos y detenciones de periodistas se efectúen, cuando hubiera lugar, mediante trámites legales y no de manera arbitraria, como se hizo con el director del Robespierre. De hecho El Redactor General publica un artículo que dice: "El editor del Robespierre se halla, en efecto, arrestado en la prevención de Guardias Españolas hace cuatro días, sin que hasta ahora se le haya dicho quien lo arrestó ni por qué". Una arbitrariedad, que evidencia cómo se saltaba a la Junta de Censura, la única que debía de juzgar en materia de libertad de imprenta y que, en definitiva, mostraba la reacción de la Regencia frente a los que la atacaban (Solís, 1987: 337).

Desde el arresto de Fernández Sardino hasta su puesta en libertad el 15 de febrero de 1812, su mujer y su hermano solicitaron clemencia, dando a conocer el suceso por toda España. Lo curioso del proceso que se llevó a cabo contra El Robespierre y su autor, reside en el hecho de que la Junta de Censura de Cádiz no encontró delito alguno en los cinco primeros números a pesar de su tono exaltado, pero consideró infamatorio y subversivo de las leyes el 6; y subversivo y esencialmente sedicioso el 7 , los dos dedicados al general Carrafa ( $\mathrm{La}$ Parra: 1984: 107-108), como veremos a lo largo de los Diarios de Sesiones de las Cortes, fuentes originales utilizadas en esta investigación. Este trabajo pre- 
Límites en el ejercicio de la libertad de imprenta.

El proceso de las cortes de Cádiz contra el Robespierre español

tende dar a conocer el estudio de estos hechos por los diputados, los límites del reglamento de libertad de imprenta y las medidas que se tomaron para evitar que casos similares se pudieran producir en otros periódicos.

\section{LA DENUNCIA CONTRA EL ROBESPIERRE ESPAÑOL. LAS DEFICIENCIAS DE LA LEY DE IMPRENTA}

El caso del Robespierre Español, amigo de las leyes nos aporta una serie de elementos que determinan los ataques a la libertad de imprenta, las intrigas políticas y la confusión legal que se generó en algunos procesos referentes a problemas con la prensa. También hay que destacar que este caso sirvió como un referente para futuros impresores, que fueron testigos de la acción de las Cortes contra una publicación.

El Diario de Sesiones de las Cortes abre el debate del 6 de julio de 1811 con la lectura de una denuncia por parte de una representación de Francisco Periu, impresor de la Isla de León, y a nombre del autor del Robespierre Español. El sábado 29 de junio se presentó a las 12 de la noche en la imprenta el gobernador militar de la zona acompañado de un escribano y sin que procediese notificación alguna de la Junta de Censura provincial, ni de la Suprema, le mandó suspender la impresión del número 10 del periódico El Robespierre Español bajo la excusa de que no era lícito trabajar en días festivos, pidiéndole además el nombre del autor de dicha publicación. Para este impresor la actuación es contraria a la seguridad que a todo ciudadano ofrece la ley de la libertad de imprenta y solicita la actuación de las Cortes para castigar estos hechos.

Se queja dicho Periu de este proceder, como contrario a la seguridad que a todo ciudadano ofrece la ley de libertad de la imprenta; y concluye con decir que tamaños atentados merecen un castigo ejemplar, con que se hagan las Cortes temer de los malvados, ya que se han hecho amar y respetar de los buenos (Diario de Sesiones de las Cortes Generales y Extraordinarias número 277. Sesión del día 6 de julio de 1811, p. 1412).

La sesión se ilustra con las aportaciones de la Junta de Censura de la provincia de Cádiz, que afirma haber calificado los siete primeros números de El Robespierre español cumpliendo las órdenes del Consejo de Regencia, acompañando esta documentación con una denuncia del duque de Híjar contra el número $6^{\circ}$, y una querella a instancia del teniente general D. Juan Carrafa, contra el número $7^{\circ}$. De la calificación de los números se estimó que el $6^{\circ}$ era infamatorio y subversivo, y el $7^{\circ}$ igualmente subversivo y sedicioso. Cuando se practicaron las diligencias contra este periódico, de conformidad con la ley de libertad de imprenta, y se esperaba que el autor de dicha publicación pidiera copia de la censura, redacta un artículo en el núm. 10 bajo el título "Desgracia del núm. $7^{\circ}$ de El Robespierre..." en el que se calumnia a la Junta. Por ello, hacen la pertinente exigencia de responsabilidad, que aportamos aquí según viene recogido en el Diario de Sesiones: 
Haga V. M. resplandecer su justicia en la obra de restituir su buen nombre y fama a los que por fieles observadores de la ley se contemplan con dolor ultrajados hasta la infamia por una detestable e inocua calumnia; y el autor de ella, que en el exceso de su frenético delirio, ha caído en la extravagante sandez de jactarse en la página 157, línea 15, de que "su alma es tan indomable como los planetas," caiga domado por la severa justicia de V. M. bajo el yugo de la ley. Halle en la vergüenza de su pública retractación el abatimiento de su jactancioso e insolente orgullo, y en la pena condigna a su calumnia e impostura, aprenda a no atentar en lo sucesivo al honor del ciudadano que, observando las leyes, vive bajo su salvaguardia (Diario de Sesiones de las Cortes Generales y Extraordinarias número 277. Sesión del día 6 de julio de 1811, p. 1412).

El diputado liberal por Extremadura Oliveros hace un estudio sobre el modo de proceder que debe tener el juez. En el artículo $5^{\circ}$ se dice que los jueces y tribunales procederán en la averiguación y calificación de los delitos que se cometan en el abuso contra la libertad de imprenta, según lo que establece el reglamento y las leyes. Entiende que la remisión a la legislación permite completar los posibles vacíos del reglamento, en base a ello y en tanto que la ley dice que, si hay motivos para sospechar que una persona es sediciosa, se puede actuar contra ella y detener. Señala que da igual si es sospechoso de crimen antes o después de la publicación del impreso puesto que las leyes autorizan para perseguirlo en todo tiempo y lugar. Además, lo equipara con los delitos de robo y asesinato en cuanto a la actuación previa que se debe tener, pues los posibles indicios conllevan la detención del presunto individuo, para posteriormente aclarar los hechos y su autoría. Reconoce que sería preferible que la propia ley de imprenta regulase el modo de enjuiciar, pero que, como no lo hace, hay que remitirse a otras leyes especiales. Su última afirmación destaca que la ley no es oscura, y que los jueces pueden ponerla en ejecución.

El diputado Valiente (se encontraría entre los 'serviles') hace un discurso a favor de la libertad de imprenta calificándolo como uno de los derechos inherentes a la dignidad del hombre, que hay que respetar, venerar y cumplir con la mejor buena fe. Dice que en España nunca fue permitido criticar con franqueza al Gobierno, un hecho evidente que puede ser contrastado en los estudios de los Diarios de Sesiones de las Cortes que evidencian cómo las referencias políticas son objeto de merma cuando atacan las estructuras de poder del Ejecutivo. Sin embargo reconoce que esta ley que ha cortado las trabas de la censura, que sirve para ilustrar a la Nación y que haciéndose buen uso de la libertad que expresa no habría razón para impugnarla, no ha sido bien utilizada. Reconoce que la mayor parte de periodistas y escritores han entendido mal esta libertad, pues no respetan nada. Con esta contundencia hacía su discurso Valiente:

Por desgracia se ha entendido mal de parte del mayor número de los periodistas y escritores, pues vemos que no se respetan las leyes fundamentales, ni las costumbres, ni el decoro público, ni el derecho sagrado de conservar el buen nombre y la opinión; en una palabra, cuando más nos importa amarnos y reunirnos, parece que solo se escribe para apartarnos del objeto principal, disminuyendo la fuerza, que unida es invencible, 


\section{Límites en el ejercicio de la libertad de imprenta. El proceso de las cortes de Cádiz contra el Robespierre español}

y partida y destrozada es más contra nosotros que contra el invasor de nuestro suelo (Diario de Sesiones de las Cortes Generales y Extraordinarias número 277. Sesión del día 6 de julio de 1811, p. 1414).

Valiente se refiere a los impresos que los diputados están manejando donde además de los elementos anteriormente comentados, se introduce un nuevo dato pues dice que "se habla de generales ya juzgados por el tribunal competente sin nota que degrade el inestimable bien de la reputación y de la fama; y sin embargo son presentados a la faz del mundo con los más negros colores". Piensa que no es justo que se permita que determinados ciudadanos sean insultados por "las plumas licenciosas" de determinadas publicaciones. Introduce referencias patrióticas al hablar de España exponiendo que "a la Patria le interesa conocer delitos que no fueron tenidos en cuenta en juicio y castigarlos, porque las leyes y la decencia permiten actuar de esta manera, pero no se puede permitir el abuso que algunos hacen de la libertad de imprenta". Llega incluso a mencionar que de estos ataques no está libre ni la Monarquía:

Se habla también en los mismos impresos de los grandes, de esta clase excelsa, que en una Monarquía ilustra el Trono y sirve a mantener el equilibrio $\mathrm{V}$. M. ha oído lo que se dice de su cuna, y yo no lo repetiré porque me sonrojo de traerlo a la memoria. No es esto ilustrar, no es dirigir las operaciones del Gobierno, no es presentar la conducta política de los funcionarios. Será pues infamar la santidad del matrimonio, será pretender que en nuestra Monarquía no haya clases; que haya ultrajados y quejosos; que dividamos nuestra fuerza y que en el caos y en la división halle el enemigo cuanto pueda desear para el logro de sus intentos (Diario de Sesiones de las Cortes Generales y Extraordinarias número 277.Sesión del día 6 de julio de 1811, p. 1414).

Valiente habla del concepto de verdad y su importancia frente a hechos que se manifiestan como falsos. Reconoce que la nueva ley de la imprenta es insuficiente para establecer los casos de injuria a la Junta Provincial, pues no aclara los trámites procesales. Valiente expone las posibilidades de recursos que tienen los autores de las injurias, resaltando los defectos que aprecia:

Para perseguir la persona de los escritos que resulten reos, la nueva ley concede a estos el derecho de exigir cuatro exámenes ó revisiones de las obras delatadas: las dos primeras por la Junta de provincia, y las dos restantes por la Suprema, que reside en el lugar del Gobierno. La de provincia se queja por ultrajada en el ejercicio de sus funciones; no tienen jurisdicción para hacerse respetar; las ofensas por el mal uso de la libertad de la imprenta se han de calificar por las censuras de ley; ella no puede hacer las dos primeras en su propia causa; la Suprema no admitirá el negocio sin aquel previo requisito; no hay otra designada por $\mathrm{V}$. M. que supla la función de la de provincia, y á presencia de estos inconclusos principios tengo sobrada razón para oír con asombro que la junta, quejosa o agraviada "ha debido procurar que V. M. provea de remedio en este caso (Diario de Sesiones de las Cortes Generales y Extraordinarias número 277. Sesión del día 6 de julio de 1811, p. 1415).

El diputado Valiente reconoce que en los procesos en los que se injuria a las personas mediante impresos notoriamente infamatorios y subversivos se debe 
proceder contra los autores sin esperar los efectos de las cuatro revisiones, cuyo curso es lento y eterno. Para fundamentar esta idea, y hacer un proceso más ágil, menciona la máxima fundamental de la jurisprudencia de ese momento (según sus propias palabras) en virtud de la cual "en los delitos públicos o notorios el orden es no guardar orden". En cierta manera lo que se quiere decir con esta expresión es que, para conseguir una justicia ágil y eficaz, debemos saltarnos los plazos y pasos legislativos creados, buscando un enfoque jurídico más pragmático que dé una solución y no se pierda en los trámites formales. Insiste en la idea de que hay que facilitar medios de resolución, aún no estando previstos por la ley de imprenta. Señala que hay fiscales que pueden implicarse en este asunto y ser parte activa, promoviendo la actuación jurídica, de hecho destaca que hay dos en la Audiencia de Sevilla.

Por su parte, Argüelles (diputado liberal por Asturias) reconoce que el mal se encuentra en el propio reglamento de la imprenta y va a centrar su intervención precisamente en el análisis de las deficiencias con las que cuenta el texto legal. Estos datos son importantes porque determinarán en 1813 una propuesta de reglamento que solventará muchas de las cuestiones que quedaban incompletas en el decreto sobre libertad política de imprenta de 1810. Inicia su exposición diciendo que se han cometido infracciones de la ley de libertad de imprenta por no haber observado sus artículos las Juntas de Censura. Para demostrarlo lee el artículo 15 del reglamento que establece que "las Juntas de Censura tendrán la obligación de revisar las obras que le remite el Poder ejecutivo o justicias respectivas"; y añade que "y si la junta censoria de provincia juzgase, fundado su dictamen, que deben ser detenidas lo harán así los jueces, y recogerán los ejemplares vendidos". Reconoce que la idea central de este artículo esta clara, la Junta de Censura revisará, calificará y devolverá al órgano pertinente (sea el Gobierno o un tribunal) la obra o texto enviado con un dictamen fundamentado. Ésas son sus funciones y no debe abarcar más, pues actúa como un perito que da su parecer en la materia que se le consulta. Además, reconoce que la redacción del texto legal es correcta y que "más cláusulas en el artículo serían redundantes, no necesarias y más bien dirigidas a ofender e insultar el sentido común de los mismos censores"1.

Este diputado va a completar su discurso haciendo exposición de algunos casos de impresos que hasta ese día habían sido denunciados, con lo que va a contestar a aquellos que proclaman la insuficiencia de la ley. Señala que los impresos que son denunciados por una autoridad lo serán por contener principios o ideas subversivas, pues no es creíble que de oficio ninguna autoridad pública sea apoderada de injurias personales de ningún particular. Establece un matiz diferenciador con las denuncias individuales y, además, añade que a la Junta de Censura de Cádiz le han llegado varios números de impresos denunciados por el

'Véase Diario de Sesiones de las Cortes Generales y Extraordinarias número 277. Sesión del día 6 de julio de 1811, p. 1416. 


\section{Límites en el ejercicio de la libertad de imprenta. El proceso de las cortes de Cádiz contra el Robespierre español}

Ministro de Gracia y Justicia, que califica como "agente muy principal del poder ejecutivo". Con un tono irónico reconoce que la acción del Ministro de Gracia y Justicia demuestra la diligencia e interés del Gobierno al intervenir en estos asuntos, por lo que sería innecesario encargar a un funcionario la denuncia de libelos.

$\mathrm{Y}$ he aquí, Señor, cómo no es necesario que la ley de la libertad de imprenta encargue a ningún funcionario público la denuncia de libelos, porque la experiencia nos demuestra que la diligencia e interés del Gobierno es más eficaz que todas las leyes, y porque en el juicio de todo hombre que razona encargar lo que el Ministro de Gracia y Justicia ha hecho por sí mismo sería suponer al Gobierno indolente e ignorante (Diario de Sesiones de las Cortes Generales y Extraordinarias número 277. Sesión del día 6 de julio de 1811, p. 1416).

En su intervención reconoce que, el Gobierno y el fiscal del Consejo Real fueron diligentes denunciando a la Junta de Censura el número o los números del periódico objeto de queja. Tan sólo quedaba que la Junta de Censura remitiera al Ministro de Gracia y Justicia la calificación para que éste se la entregara al juez o tribunal, con objeto de que se viera con prontitud el expediente, más sabiendo que el Gobierno era parte activa en el proceso. Una vez realizado esto se notificaría la censura al editor o en su defecto impresor porque el Gobierno tiene la obligación de activar los tramites de la ley para que, concluidas todas las censuras, se impusiera al autor, si hubiera lugar, la sanción que corresponda con la finalidad de que sirva de escarmiento a futuros autores. Después de hacer este repaso, por los trámites que debe seguir un proceso contra un escrito, Argüelles afirma que cuando el Gobierno no encarga expresamente al tribunal o juez correspondiente perseguir al autor de oficio, y teniendo la censura, éste podrá hacerlo de oficio; además, dicha idea no debe ser recogida en un artículo independiente pues se da por entendida del resto de artículos que conforman el texto legal, especialmente el número 15.

Esto es más claro que el día para el que no tiene por objeto que todos seamos necios o ciegos. El juez, al ver que la censura califica el escrito de subversivo, ya conocería que no eran coplas ó canciones de puro pasatiempo. Reconocido por el juez el interés público en castigar delitos tan trascendentales, ¿no tenía en su arbitrio y en su obligación activar los trámites de la ley? ¿Son todas nuestras leyes criminales más claras en el señalamiento de las obligaciones de un juez, luego que éste ha comenzado a entender en un proceso o causa de entidad? En este caso ¿sería necesario encargar expresamente al juez lo que el sentido común aconseja a todos los hombres? Recibida la censura y viendo por ella que el Estado peligra o que el Gobierno esta insultado, ¿no tiene en su arbitrio acelerar con toda la legalidad las providencias que son de su inspección? (Diario de Sesiones de las Cortes Generales y Extraordinarias número 277. Sesión del día 6 de julio de 1811, p. 1416).

Argüelles va a criticar la falta de acción por parte de los jueces para intervenir en el asunto, incluso les anima a buscar medios con los que agilizar su actuación sobre todo cuando estamos con escritos cuya capacidad de propagación es 
muy rápida si no se toman medidas cautelares. Menciona los artículos $4^{\circ}$ y $5^{\circ}$ del decreto de libertad de imprenta, en concreto las partes que señalan que las leyes serán observadas en el castigo de los que escribiesen libelos infamatorios, calumniosos y subversivos. En sus reflexiones precisa que se derogaron aquellas leyes que establecían la previa censura, y que la nueva ley permite al acusado apelar la censura frente a la Junta de Provincias y la Junta Suprema. Reconoce que los jueces o tribunales son el legítimo conducto entre las Juntas de Censura y los escritores o impresores de textos denunciados, y que esto se puede inferir de la lectura de los artículos 5 y 15 del reglamento.

Vuelve a sacar otro caso para completar su exposición, en concreto señala que la Junta Suprema de Censura en la calificación del escrito de D. Lorenzo Calvo de Rozas procedió a notificarle el dictamen, que consta en la Gaceta del Gobierno de 20 de junio, por medio del secretario que actúa en la Junta. Dicho individuo pasó a hacer lo que sólo le correspondía al juez o tribunal competente, habiéndose por lo mismo expuesto al ultraje u ofensa que se le hizo, provocada quizá por la irregularidad de la notificación. Argüelles señala que si la notificación "hubiera sido hecha a nombre del juez o tribunal, la injuria hubiera recaído también sobre su autoridad, la cual hubiera sido más respetada y sería vindicada según previenen nuestras leyes contra los desacatos hechos a la justicia"2.

Los delitos no se disculpan nunca, ni quedan impunes porque otro falte a su deber, es verdad pero las equivocaciones $u$ omisiones en el cumplimiento de lo que debe observarse son menos disimulables en la autoridad, que debe dar ejemplo. $Y$ hubiera sido muy de desear que la Junta Suprema de Censura no se hubiese expuesto al insulto que experimentó en el caso que se ha citado, y aún más que la provincial de Cádiz no hubiese dado motivo con lo ocurrido en la Isla de León al insolente, injurioso y atrevido escrito de que tan justamente se queja á las Cortes (Diario de Sesiones de las Cortes Generales y Extraordinarias número 277. Sesión del día 6 de julio de 1811, p. 1417).

Argüelles termina su exposición animando al resto de miembros de las Cortes para que sigan discutiendo y aclarando las dudas que puedan plantearse en torno a la libertad de imprenta, porque, según su testimonio, sería lamentable que los abusos de dicha libertad y la falta de entendimiento legislativo de los tribunales, pudieran acabar con una ley que tanto costó aprobar tras acalorados debates. Su último manifiesto, fruto del sentimiento de un hombre que trabaja y lucha por hacer realidad la libertad de escribir en su máxima expresión, es un grito de esperanza, un intento de hacer luz en la confusión de las opiniones, una forma de abrir camino y demostrar a los diputados el preciado don que es la libertad de imprenta. Con estas reflexiones se quedó pendiente de discusión este asunto.

\footnotetext{
${ }^{2}$ Véase el Diario de Sesiones de las Cortes Generales y Extraordinarias número 277. Sesión del día 6 de julio de 1811, p. 1417.
} 
Límites en el ejercicio de la libertad de imprenta. El proceso de las cortes de Cádiz contra el Robespierre español

Los que la crean perjudicial, o contraria a sus intereses, o incompatible con el sistema de gobierno que se haya formado, no se contentará con nada menos que con su abolición. Poco importa destruirla, derogándola o haciéndola nula y nominal con enmiendas y adiciones. Yo sé bien lo que esto significa, y me admiro de mí mismo cuando veo que me he dilatado en reflexiones, que o no son necesarias, o son inútiles. El resultado por fin de todo lo ocurrido hasta el día, vendría a ser que con conjurarse solo dos periodistas á abusar de la libertad de escribir y empeñarse los tribunales en no entender la ley, vendría esta al suelo, y pagaríamos todos los delitos de pocos, o seríamos víctimas de una infame trama (Diario de Sesiones de las Cortes Generales y Extraordinarias número 277. Sesión del día 6 de julio de 1811, p. 1418).

\section{EL CUMPLIMIENTO DEL REGLAMENTO DE LIBERTAD DE IMPRENTA. CONFLICTO COMPETENCIAL ENTRE LAS CORTES, JUNTAS DE CENSURA Y TRIBUNALES DE JUSTICIA.}

La sesión del día 7 de julio va a profundizar en muchos de los prolegómenos que fueron planteados en el inicio de este caso. A lo largo de esta sesión se entra en un debate sobre la competencia en la calificación de escritos, mostrando la rivalidad existente entre las Cortes, Juntas de Censura y Tribunales de Justicia.

Zorraquín (diputado liberal suplente por Castilla) señala que se sentiría por satisfecho si, con estas discusiones, se les pudiera aportar a los jueces y magistrados, encargados de la ejecución del reglamento de imprenta, un conocimiento más exhaustivo de sus obligaciones, evitando casos como el que estamos analizando. No obstante, le preocupa que, aún con este dilatado proceso, los diputados sigan manteniendo dudas, algo que, como estamos comprobando a lo largo de las diferentes sesiones, es habitual. En su exposición aclara que no tiene intención de defender ni acusar los escritos del Robespierre pues al Congreso no le corresponde calificar el mérito de éstos u otros papeles sino sólo velar por el cumplimiento de la ley y aclarar, variar o modificar las disposiciones legales, si con ello entiende que es para el bien de la Nación. De nuevo, otro diputado exalta los valores nacionalistas dentro de su discurso, pero dejando muy claro que el papel de las Cortes es legislar, pues muchas veces vemos cómo se confunden las funciones y se le atribuye a dicho órgano un papel ejecutivo, que corresponde más al Gobierno, o un carácter judicial, que es competencia de los tribunales.

Zorraquín insiste en que la Junta debía haber notificado al juez de crimen su calificación, igual que hizo con el Consejo de Regencia, sin declarar cómo se debía proceder contra el autor del escrito, pues en parte es culpable de los sucesos que se desarrollaron posteriormente. Tras aclarar la improcedencia de la actuación de la Junta, Zorraquín analiza si es oportuno el recurso que se hizo a los miembros de Cortes. Manifiesta que no está conforme con la idea de que en el número 10 del Robespierre se atacase a la institución de la Junta pues el autor debería demostrar que dicho órgano es inútil y no conviene a la libertad de imprenta. El autor del periódico manifiesta que su censura no está arreglada a la ley, y eso para Zorraquín no es atacar a la institución, del mismo 
modo que cuando se recurre una sentencia a un órgano superior se alegan los defectos del fallo provisional. Si hubiera advertido que se atacó a la institución de la Junta, entendería legítimo el recurso que ésta interpone a las Cortes, pero esto no es así. Es importante resaltar que Zorraquín en su discurso hace constantes comparaciones entre los tiempos pasados, propios del absolutismo y Antiguo Régimen, y los presentes, caracterizados por una nueva forma de manifestar los cambios, que las revoluciones liberales están impregnando en la sociedad. Este nuevo contexto les lleva a entender la vida política de forma diferente; también remarca la idea de legalidad como parámetro para regir los designios de un pueblo.

Si en realidad se hubiese tocado la institución de la Junta, y se pretendiera su variación o reforma, yo confesaría que el recurso de ella a V. M. era legítimo, era oportuno, y pertenecía propiamente al Congreso; pero no siendo esto así, creo que no debe admitirse su exposición, y que el agravio debe considerarse hecho a simples ciudadanos. ¿Si en los tiempos anteriores, y aun en los presentes, se hiciese un agravio a todos los individuos de un tribunal, sería necesario acudir al soberano para que los desagraviase? Es indudable que no. Está bien detallado en las leyes cuándo ha de considerarse un juez o tribunal inhibido del conocimiento de la causa que ante él pende (Diario de Sesiones de las Cortes Generales y Extraordinarias número 278. Sesión del día 7 de julio de 1811, p. 1421).

Señala que el autor del Robespierre debe acudir a los tribunales y a los jueces para demandar el ataque contra la libertad de imprenta y, lógicamente, estudiar más exhaustivamente todo el caso. Mantiene que no se ha respetado el reglamento de la libertad de imprenta hasta la fecha e ilustra su afirmación exponiendo que, desde que el juez del crimen de Cádiz remitió a la Junta de Censura el escrito, no se han tomado medidas ni se ha castigado el delito con la pena correspondiente. Aquí asistimos a un juicio a priori, se califica de delito un hecho que esta estudiándose, con lo cual hay un dictamen previo y un uso del lenguaje inapropiado que condena las situaciones.

Zorraquín pone de manifiesto que hay una clara intención por parte de algunos sectores de acabar con la libertad de imprenta y, como no saben otra forma de derogar la ley, deciden crear polémica con la presentación de casos escandalosos que evidencian la mala utilización de dicha libertad. Se alude a los peligros que la imprenta está ocasionando al Gobierno y se pide la condena como una forma de resarcir ante tanto mal anunciado. Ante estos hechos, este diputado clama en defensa de la libertad de imprenta y reconoce que los males del Gobierno no son fruto del abuso que puedan cometerse en la publicación de escritos. Construye su testimonio bajo una base legalista que reconoce el poder de la ley para remediar los males del Estado. Sólo exigiendo un cumplimiento exhaustivo de los preceptos legales podremos garantizar el futuro y salvar a la Nación de los males que envenenan su sociedad. En esa lucha de pensamientos, que envuelven a las Cortes, la libertad de imprenta se convierte en un espíritu de luz que salvará al pueblo de perecer en las llamas de un infierno marcado por la traición y la 


\section{Límites en el ejercicio de la libertad de imprenta. El proceso de las cortes de Cádiz contra el Robespierre español}

conspiración. Sólo afrontando con valor estas reflexiones, podrían sobrevivir a la merma intelectual que se podía avecinar.

Pero Señor, opongámonos a esta trama; conozcan todos que los males que puede ocasionar el abuso de la libertad de imprenta no son atribuibles á esta, que están prevenidos los medios de remediarlos, y que cuantos pueden sufrirse en el día no son efecto de una tan saludable y meditada institución, sino de la intriga, de la mala intención y del deseo de nuestra esclavitud, y por último, que todo desaparecerá en el momento que se exija una escrupulosa y rigurosa observancia de las leyes, que tanto anhela V. M (Diario de Sesiones de las Cortes Generales y Extraordinarias número 278. Sesión del día 7 de julio de 1811, p. 1422).

Aner, diputado catalán caracterizado por sus intervenciones en los procesos sobre escritos, realiza algunos comentarios en torno al reglamento de la libertad de imprenta. Frente a aquellos que defendían que dicho texto legal contenía todos los posibles casos que en la práctica se pudieran plantear, sostiene que el reglamento es defectuoso al menos en el supuesto que estamos analizando, pues no provee solución cuando una Junta de Censura es calumniada o insultada. No se sabe quién debe calificar el escrito, como tampoco se aclara si corresponde hacerlo a la Junta Suprema, cuando la afectada es una Junta provincial. Por ello, se hace necesario que el legislador aclare la ley y se incluyan preceptos que regulen la casuística emergente.

Algunos señores preopinantes, a fuerza de razones, han querido persuadir que el reglamento de la libertad de imprenta está perfecto en todas sus partes, que provee á todos los casos, y en una palabra, que es un dechado de perfección. Para que yo pueda convencer a V. M. de lo contrario, propongo el siguiente dilema: o el reglamento de la libertad de la imprenta previene este caso y todos los que puedan ocurrir, o no los previene: ó el reglamento está perfecto en todas sus partes, ó no; si lo es, y está en él prevenido todo, V. M. debe desatenderse al momento de todo recurso ó consulta: y si no previene todos los casos, es preciso que el legislador aclare la ley, la interprete, explique o adicione (Diario de Sesiones de las Cortes Generales y Extraordinarias número 278. Sesión del día 7 de julio de 1811. p. 1422).

Borrull (diputado valenciano realista) centra su intervención destacando que es la Junta de Censura la que se acerca a las Cortes reclamando justicia, puesto que no puede acudir a los tribunales ya que esta opción no estaba designada ni en leyes anteriores, ni en el reglamento de la libertad de imprenta. Al igual que otros miembros va a destacar algunas deficiencias que aprecia en el reglamento y en el desarrollo de los posibles procesos. Se pregunta qué magistrado es competente para conocer las injurias en cualquier impreso contra las Juntas provinciales de Censura. Las Juntas fueron creadas con independencia del Poder ejecutivo y de todos los Consejos y Tribunales, y ahora, cuando se produce el problema, no se sabe a quién acudir. También observa que, lo mismo que ha ocurrido en la Junta de Cádiz, puede suceder en otras provincias, por lo que entiende que deben tomar los diputados una decisión al respecto que pueda servir de referente. 
Este diputado plantea que los defectos del reglamento pueden ocasionar serios perjuicios, especialmente en aquellas provincias lejos de Cádiz que, ante un caso similar, consultarían a las Cortes y, dada la distancia territorial o las dificultades de navegación, tardarían muchos meses en conseguir una solución. Menciona a las Juntas de Galicia, Asturias, Cataluña o Valencia como lugares distantes, y piensa que las Audiencias territoriales podrían conocer de los asuntos concernientes a la imprenta, nombrando a sujetos para que entiendan de la censura de obras, en los casos de vocales que fallezcan, enfermen o sean recusados. Su postura es buscar una forma ágil y práctica de solventar los conflictos, por ello pretende establecer una serie de canales que eviten que otras Juntas se vean afectadas por cuestiones similares.

El político Caneja (diputado por León) va a realizar un discurso más severo, que tiene ciertos matices patrióticos con alguna exaltación de los valores nacionales, pero que encierra también la postura de un hombre comprometido con la libertad de imprenta, que se siente orgulloso de haber participado en la votación de este texto legal, y que es consciente de que, a pesar del valor que tiene dicho texto, no es perfecto:

Es ciertamente escandaloso que hasta ahora no hayamos visto castigado a ninguno de los autores de tantos libelos como la opinión pública ha condenado de subversivos, sediciosos y aún incendiarios, y es ciertamente cierto que si hubiera habido algún ejemplar castigo, como ha debido haberle en observancia de las leyes, el abuso no habría llegado al extremo que vemos, ni la Patria sufriría los males que por desgracia sufre ya por él. Pero no dejo por eso de convenir con otros señores que dicen que es necesario hacer alguna adición a la ley (Diario de Sesiones de las Cortes Generales y Extraordinarias número 278. Sesión del día 7 de julio de 1811, p. 1424).

Este diputado señala que existen una serie de casos sobre libertad de imprenta que no fueron recogidos en el reglamento. Hace una retrospectiva al momento de adoptar el reglamento y reconoce que, en aquel momento, era impensable que se fueran a producir ataques contra el órgano que se creaba para calificar escritos. Ante esta realidad, no pueden cerrar los ojos y dejar que determinados autores actúen con impunidad, por eso quiere alentar a los diputados a buscar algo de luz en estos casos. El texto legal dice que "los jueces y tribunales conocerán de los abusos de la libertad de imprenta", pero al igual que muchos diputados, él desconoce cuál es el tribunal o juez competente para conocer este asunto.

La calificación del escrito es otra de las constantes preocupaciones que se vierten en el verbo fluido y cuidado de los diputados, pues entienden que la Junta de provincia estaría incapacitada para realizarla al ser objeto de los ataques del escrito. Caneja va a reflexionar sobre los peligros que giran en torno a la libertad de imprenta y plantea ciertos dilemas. Reconoce que, las Cortes tras crear las Juntas de Censura y dotarlas de independencia frente al Poder ejecutivo, para que no influyera en sus calificaciones, luchando por hacer realidad los conceptos de libertad de imprenta, ahora las hacen depender del Poder judiciario: 


\title{
Límites en el ejercicio de la libertad de imprenta. El proceso de las cortes de Cádiz contra el Robespierre español
}

\begin{abstract}
Además, Señor, yo creo que mis dignos compañeros, que opinan de diferente manera, no han previsto que el resultado de su opinión, si se adoptara, sería contra sus deseos la ruina de la libertad de imprenta. V. M. ha creado las Juntas de Censura para sostenerla, ha nombrado por sí mismo a sus individuos, siendo éstas las únicas elecciones de destinos que se ha reservado el Congreso, y ha puesto estas corporaciones bajo su inmediata protección, sacándolas de toda dependencia del poder ejecutivo, para que la influencia de este no pudiese en ningún tiempo quitar a aquellos la libertad necesaria en sus calificaciones. ¿Y cometeremos ahora la imprudente inconsecuencia de echar por tierra el apoyo más firme de la libertad de la imprenta, quitándoseles a sus calificadores, sujetándolos y haciéndolos dependientes del Poder judiciario, y por consiguiente del ejecutivo? (Diario de Sesiones de las Cortes Generales y Extraordinarias número 278. Sesión del día 7 de julio de 1811, p. 1425).
\end{abstract}

En esta afirmación encontramos uno de los elementos heredados del constitucionalismo francés y del filósofo Montesquieu, la separación de poderes. Existen tres poderes separados e independientes como el Poder legislativo, representado en las Cortes, el Poder judicial, formado por jueces y tribunales, y el Poder ejecutivo, materializado en el Gobierno. Sin embargo, de las palabras de Caneja advertimos que, en este proceso de formación de poderes, la independencia es más un propósito a alcanzar que una realidad material, pues considera que someter el control al Poder judicial es como someterlo al ejecutivo. Esta relación podría venir por el hecho de que sería el Gobierno quien designase a los miembros que pueden formar los Tribunales, con lo cual se abre una perspectiva de gran interés sobre el grado de independencia de estas instituciones y las presiones políticas a las que estuvieron sometidas. No obstante, hay que destacar que, para Caneja, la principal preocupación es garantizar esa libertad de imprenta, y evitar, en lo posible, la confusión de funciones que se está suscitando entre los diferentes poderes.

\section{LAGUNAS LEGISLATIVAS. INTERPRETACIONES DEL TEXTO LEGAL EN EL MARCO DE LA PRÁCTICA PERIODÍSTICA}

En las últimas sesiones de las Cortes de Cádiz sobre el caso de El Robespierre Español, los diputados que intervienen destacan algunas lagunas legislativas que vician el ejercicio práctico de la libertad de imprenta. Así, el diputado suplente por León Villagómez reconoce que, después del esfuerzo que supuso el reglamento de la libertad de imprenta, no es completo ni contempla algunos supuestos que la práctica está dando a conocer. Además, manifiesta cómo los jueces de censura han sido maltratados, desobedecidos e insultados por los autores de los escritos, quedando indefensos sin saber qué hacer y a dónde acudir pues el reglamento no dice nada al respecto. Todo esto hace necesaria una interpretación de los preceptos legales y una aclaración, siendo las Cortes un foro propicio para hacer estas declaraciones. Señala que el capítulo del decreto de libertad de imprenta, por el que se ordena que los autores de los impresos subversivos de las leyes fundamentales de la monarquía sean castigados con la pena de la ley y demás 
que señala el reglamento, está lleno de lagunas y dificultades. Dicho texto sólo habla de los impresos que impugne la monarquía directamente, dejando fuera otros muchos escritos que pueden generar desconcierto de un modo peligroso, bien desacreditando las leyes del gobierno o mediante un abuso perjudicial de la libertad de imprenta. Así lo explicaba el diputado:

No se habla más que de aquellos escritos que impugnen la monarquía directamente, pues hay otros muchos que traerán la insubordinación y desconcierto de un modo muy peligroso por estos dos medios que no se precaven con claridad: el primero escribiendo y desacreditando las leyes que gobiernan y han estado en observancia, y que les conviene a los escritores reformar por su solo juicio; y estando congregada la Nación para tan grande obra, no es dado a ninguno abrogarse esa autoridad sin exponerse a las funestas consecuencias que nos podría ocasionar una libertad de imprenta tan mal entendida, y en las actuales circunstancias perjudicial. Por otro segundo medio es de temerse un abuso perjudicial de la libertad de imprenta sin que sea suficiente el capítulo IV referido del decreto de las Cortes para evitarle (Diario de Sesiones de las Cortes Generales y Extraordinarias número 278. Sesión del día 7 de julio de 1811, p. 1426).

La idea del interés de los escritores por reformar algunas leyes puede resultar de importancia, sobre todo si planteamos la posibilidad de que uno de los deberes del periodista es denunciar aquellos elementos del sistema que no funcionan. Si un escritor advierte una deficiencia en la ley, sería legítimo denunciarlo en su publicación, con lo cual la referencia de este diputado hay que entenderla con matices pues, en el fondo, se está desacreditando uno de los valores de toda democracia como es poder expresar las ideas y opiniones en libertad, máxime cuando es una legislación que tiene efectos prácticos en los ciudadanos. Su afán por matizar algunos puntos del decreto sobre libertad de imprenta llega al extremo de ejemplificar su exposición con supuestos escritos, que critican y se burlan de las providencias o mandato de un jefe o gobernador de una provincia. En este caso se entendería que el escrito no es subversivo de las leyes fundamentales de la monarquía, a pesar de que la Junta de provincia lo calificase como sedicioso; estas referencias evidencian las deficiencias del reglamento sobre libertad de imprenta. En igual situación de indefensión se encontrarían los libelos en Barcelona o La Coruña, casos en los que, dada la distancia, los efectos de propagación de un escrito serían mayores que la capacidad de reacción por parte de las instituciones. La solución puede ser buscar una fórmula para detener los escritos que tuvieran censura antes que se produjera la difusión y divulgación.

Con todas estas ideas, el diputado por Canarias Gordillo va a reflexionar sobre el verdadero sentido de estas leyes y medidas, basando su protesta en una defensa de los intereses del escritor y de la propia libertad de imprenta. Se pregunta por qué en este caso se deben hacer excepciones e ignorar las formalidades que legalmente se habían desarrollado anteriormente en el reglamento de imprenta para la calificación y censura de escritos. Se interroga por todo el procedimiento e incluso duda de los marcos establecidos para sancionar un delito. 
Límites en el ejercicio de la libertad de imprenta. El proceso de las cortes de Cádiz contra el Robespierre español

¿Por qué ha de ser suficiente el dictamen de solo nueves hombres para sancionar un delito, y casi indicar la pena que debe serle impuesta, cuando en materias de hecho y en puntos complicados sobre el espíritu e inteligencia de una expresión en doctrina política no es tan fácil que se uniformen las ideas y se concentre la opinión común? (Diario de Sesiones de las Cortes Generales y Extraordinarias número 278. Sesión del día 7 de julio de 1811, p. 1427).

Hay que señalar que tras pasar veinte días desde la última sesión sobre el caso del número 10 del periódico Robespierre, el Consejo de Regencia remitió a la Junta de Censura de Cádiz la publicación para que la calificase pero, al ser parte afectada por el texto, se hacía necesario presentar consulta previa a las Cortes. Finalmente se decidió que las Cortes calificasen aquellas partes en las que no se considerara ofendida y que fuera el Consejo de Castilla, quien conocía los hechos por comisión, el que calificara los contenidos que presuntamente ofendían a la Junta. Así queda recogido en el propio texto del Diario de Sesiones de las Cortes del día 30 de julio de 1811:

Y las Cortes, aprobando lo que propuso el Sr. Oliveros, resolvieron "que la Junta provincial, absteniéndose de censurar las expresiones con que se creía ofendida, y de las que conocía por comisión el Consejo de Castilla, diese a todos los demás asuntos que se tocan en el núm. 10 del Robespierre Español la que creyese merecía (Diario de Sesiones de las Cortes Generales y Extraordinarias número 301. Sesión del día 30 de julio de 1811, p. 1535).

No era la mejor solución pero al menos intentaba superar todo este retraso que se había producido por la falta de determinación de la libertad de imprenta. En el Diario de Sesiones de las Cortes Generales y Extraordinarias de 28 de marzo de 1813 se mandó pasar a la comisión de libertad de imprenta una consulta de la Junta Suprema de Censura, relativa a ciertas dudas acerca de si se debía o no proceder a la calificación de varios números del periódico titulado El Robespierre españoß ${ }^{3}$. El asunto analizado en esta investigación no fue el único proceso que tuvo esta publicación, sino que se vio envuelto en constantes acusaciones de menor entidad que se suscitaron por la publicación de otras tiradas.

\section{LAS REPERCUSIONES DE EL ROBESPIERRE ESPAÑOL EN EL EJERCICIO DE LA LIBERTAD DE IMPRENTA. CONCLUSIONES FINALES}

En esta lucha de intereses políticos y tras la celebración de este proceso, se evidenció que el sistema había fallado y que era insuficiente para paliar situaciones, que extralimitaban el ejercicio de la libertad de imprenta. La gran mayoría de los diputados estuvieron en contra del Robespierre, y sólo podemos encontrar pequeños reductos a favor de la libertad de imprenta, que utilizaron los debates

\footnotetext{
${ }^{3}$ Véase el Diario de Sesiones de las Cortes Generales y Extraordinarias número 808. Sesión del día 28 de marzo de 1813, p. 4905.
} 
para evitar que se derrumbaran los logros que se habían conseguido con el texto legal de 1810. Surgieron sectores que demandaban una urgente reforma del reglamento sobre libertad de imprenta, para ampliar la casuística existente y hacerla más efectiva, frente a otros que consideraban que no era necesario. Sin embargo, estas disputas también mostraron la vulnerabilidad de la libertad de imprenta, pues se destacaron sus puntos débiles, evidenciándose que no era perfecta y carecía de un contenido concreto aplicable al ejercicio práctico.

La riqueza de todos estos debates reside, no sólo en el análisis del caso del Robespierre sino en todos los temas anexos que su estudio suscita. Los debates analizados ponen de manifiesto que las Juntas de Censuras y, en concreto la de Cádiz, no fueron capaces de resolver por sí mismas los problemas en el ejercicio de la libertad de imprenta, pues tuvieron que recurrir a las Cortes para que decidieran qué hacer. Por otro lado, se aprecian las diferentes entidades interesadas en participar en el control de escritos como el Consejo de Regencia, que aún ignorando las limitaciones de la ley intenta tener presencia en estos procesos. No es de extrañar esta actitud, pues ser parte activa en la persecución y control de escritos era una manifestación de poder que serviría para controlar a aquellos escritores que intentaran calumniar o atacar a órganos institucionales.

A lo largo de los debates de las Cortes apreciamos cómo fue rechazado El Robespierre, pues los diputados no lo apoyaron. Las principales controversias surgieron respecto al modo de aplicar la ley de imprenta; los liberales entendían que el propio decreto de 1810 era capaz de evitar cualquier irregularidad en las publicaciones; los sectores contrarios estimaban que la legislación del momento era insuficiente para paliar el problema. Oliveros, Argüelles y Zorraquín, por el contrario vieron un caso de aplicación incorrecta de la ley, pues la Junta de Censura de Cádiz había ordenado el secuestro del número 10 del periódico sin preceder las correspondientes censuras, incurriendo en extralimitación de funciones, ya que sólo a la autoridad judicial correspondía la incautación de las publicaciones. El diputado Dou estimaba que la ley de imprenta fallaba al no contemplar los casos de escritos que se burlan de la Junta de Censura. Borrull consideraba que el reglamento de libertad de imprenta, al exigir cuatro censuras en cada proceso, alarga su resolución unos cuatro meses, por lo que se ponía de manifiesto la necesidad de reformar la ley de imprenta para conferirle auténtica operatividad (La Parra, 1984: 111).

El Robespierre fue finalmente objeto de condena, y su autor, Pedro Pascasio Fernández Sardino, sufrió arresto gubernativo, siendo recluido en un hospital aquejado de problemas de salud. La causa de un hombre liberal, enfrentado a los abusos del poder, quedó sepultada bajo los escombros de una realidad politizada, en la que las Cortes se habían convertido en una nueva forma de control.

A ello, debemos añadir que este caso sirvió para demostrar la escasa utilidad de la Junta de Censura, pues fueron las Cortes las que tuvieron que resolver el asunto y no se contó con medios para hacer frente a los escritos dirigidos contra ella. Por otro lado, las Cortes empezaron a manifestar las objeciones a la ley de 
Límites en el ejercicio de la libertad de imprenta.

El proceso de las cortes de Cádiz contra el Robespierre español

imprenta, y se evidencian los conflictos y diferencias con la Regencia. Hay autores como La Parra (1984: 111) que señalan que el caso de este periódico, de tono francés y carácter patriótico y exaltado, evidenció la fragilidad de la labor de las Cortes; y aunque su condena sirvió de advertencia para otras publicaciones liberales extremistas, también animó a aquellos que deseaban suprimir la regulación sobre libertad de imprenta.

Las interrogantes que se han expuesto a lo largo de este artículo son reflejo de la realidad de una legislación experimental. No obstante, también hay que entender el momento en el que se gestan, pues es un periodo histórico en el que no están muy definidos los criterios legislativos en materia de libertad de imprenta. Por ello es importante reconocer el logro que había supuesto, para los diputados de la época, sacar un reglamento sobre libertad de imprenta, aunque fuera incompleto en algunos extremos. No obstante, hay que señalar que los diputados de la época hicieron un notable esfuerzo en 1811 por recopilar los defectos más importantes de los textos legislativos, con la finalidad de evitarlos en futuras legislaciones. Los equívocos del primer reglamento sobre libertad de imprenta motivarán en 1813 una reforma en la que se incluyeron nuevas matizaciones del texto originario, reforzando el papel de las Juntas de Censura, definiendo sus funciones y características.

\section{REFERENCIAS BIBLIOGRÁFICAS}

GÓMEZ APARICIO, P. (1967): Historia del periodismo español. Madrid: Editora Nacional.

DIARIOS DE SESIONES DE LAS CORTES GENERALES Y EXTRAORDINARIAS DE CÁDIZ: Núm. 277 (6 de julio de 1811); núm. 278 (7 de julio de 1811); núm. 301 (30 de julio de 1811); núm. 808 (28 de marzo de 1813).

LABIO BERNAL, A. (2000): Diario de Cádiz. Historia y Estructura Informativa. (1867-1898). Sevilla: Grupo de Investigación en Estructura, Historia y Contenidos (GREHCCO) de la Comunicación de la Universidad de Sevilla.

LA PARRA LÓPEZ, E. (1984): La libertad de prensa en las Cortes de Cádiz. Valencia: Nau Libres.

RAMOS SANTANA, A. (1992): Historia de Cádiz. Cádiz en el siglo XIX. De ciudad soberana a capital de provincia. Madrid: Sílex.

SEOANE, Mª. C. (1992): Historia del periodismo en España. El siglo XIX. Madrid: Alianza.

SOLíS, R. (1987): El Cádiz de las Cortes: la vida en la ciudad en los años 1810 a 1813. Madrid: Sillex.

- (1971): Historia del periodismo gaditano. Cádiz: Instituto de Estudios Gaditanos, Excma. Diputación Provincial de Cádiz.

TOBAJAS, M. (1984): Periodismo Español. Notas para su historia. Madrid: Forja.

VV. AA. (2006): La guerra de pluma. Estudios sobre la prensa de Cádiz en el tiempo de las Cortes (1810-1814). Cádiz: Servicio de Publicaciones de la Universidad de Cádiz. 


\section{REFERENCIAS HEMEROGRÁFICAS}

El Robespierre Español. Amigo de las leyes, número VI, fechado el 23 de mayo de 1811.

El Robespierre Español. Amigo de las leyes, número VII, fechado el 27 de mayo de 1811.

El Robespierre Español. Amigo de las leyes, número X, fechado el 20 de junio de 1811.

\section{Breve semblanza biográfica del autor}

Jesús López de Lerma Galán es Doctor en Comunicación, Historia del Periodismo y Derecho a la Información por la Universidad de Sevilla. También tiene las Licenciaturas de Derecho y Periodismo, y ha sido Becario del Congreso de los Diputados de Madrid. Su ejercicio profesional se ha desarrollado en diversos medios de comunicación como Onda Cero, Canal Sur y Cadena Ser, entre otros. En la actualidad compatibiliza su actividad académica con su trabajo como abogado y director de comunicación.

(Recibido el 19-11-2009, aceptado el 14-05-2010) 